\title{
A Review of Authenticity Analysis of the Recovered Memories
}

\author{
Bonan Chen ${ }^{1, *}$ \\ ${ }^{1}$ University College London, Gower Street, London WC1E 6BT, UK \\ ${ }^{*}$ Corresponding author. Email: bonanchen0203@outlook.com
}

\begin{abstract}
This paper adopts the literature research method to aim to discuss the authenticity of recovered memories by summarizing the causes of formation of truly recovered memories and false recovered memories, which covers the concept of repression, amnesia and dissociation in positive, as well suggestibility in negative. A few hypothesis about other concepts of false recovered memories would also be given, such as source attribution, bias as well confabulation. At last, the methods of how to detect the false memories and suggestions of how to avoid them would be stated for both interested people, and occupational subjects who require relevant knowledge.
\end{abstract}

Keywords: recovered memory, false memory, suggestibility, source misattribution, bias, confabulation.

\section{INTRODUCTION}

Recovered memory is defined as the biased experience of recalling a previous traumatic event, such as physical or sexual abuse, which has been unretrievable to preceding conscious recollection. However, when patients mistakenly assume that they were suffered from abuse, which is not a lie and they intensely believe, while the event never occurred. This kind of memory would be determined as false recovered memory.

False memory represents the distorted recollection of an event that undeniably occurred. In 1974, the cognitive psychologist Elizabeth Loftus from the University of Washington, foremost conceived and promulgated the term "false memory", and following by the psychologist Daniel Schacter (2001) who offered seven ways how our memory failed us, which also could be called as seven sins in the memory, he classified them into three groups: forgetting, distortion, and instruction. Distortion, as socalled false memory, is consist of suggestibility, source misattribution, bias, and the extra concept of confabulation [1].

On this topic, there was a controversial debate about the authenticity of recovered memory. Certain therapists who have been exposed to trauma survivors claimed that the memories are true because they exist with an escort of extreme emotions. On the contrary, other therapists have reported recovered memory as false memory on account of that it is possible for therapists to implant the memories into patients' mind by alluding to them as being victims of abuse, which is an instance of suggestibility.

Because this field has received considerable attention from practitioners and academia, it is worth discussing and summarizing. Thus, this paper adopts the literature research method to aim to analyze the perspective from both for and against. For the false recovered memory, the hypothesis on other categories of false memory will also be mentioned except the prevailing view of the main cause as suggestibility, which is helpful for enlarging the range of detecting false memory. In the end, the methods of revealing diverse false memory and suggestions of trying to avoid false memory will be stated for applications and implications of this paper.

This paper contributes to the theoretical debate on the facticity of recovered memories, and offers solutions to the false recovered memory, in this way to help both interested people and occupational subjects such as therapists, officers or researchers who require relevant knowledge to either grasp and frame the structure by virtue of individual interest or for seeking out a relatively fair judgement during diagnosis in criminal courts. 


\section{DEBATE ON RECOVERED MEMORY}

\subsection{True recovered memory}

Conceding that the recovered memory is actual, the prime agents which lead to the obliteration of prior memory could be repression, amnesia and dissociation.

The definition of the term "repression" is vital for establishing whether or not there is confirmation for recovered memories. The psychologist Sigmund Freud offered disparate descriptions in his use as he adopted the term as rejections to menacing memories under fully conscious awareness, which could be called as suppression in his early works, later the term was subsequently altered and instead by the explanation of unconscious defense mechanisms as the subject refuses to process the distressing information with conscious awareness that was concluded as primary repression. It is literately not accessible to distinguish the primary repression, suppression or solely forgetting due to lack of retrieval cues and the passage of time for certainty.

In Williams, L. M. (1994), there were 129 female participants with priorly documented histories of sexual abuse in childhood being interviewed. The researcher has asked them specific questions about their experience of abuse, such as "Do people actually forget traumatic events such as child sexual abuse, and if so, how common is such forgetting?" As a result, $38 \%$ of participants did not recall the abuse. In fact, some respondents indicated that they were referring to avoid thinking about the abuse for a given period. This would be a closer supporting evidence for suppression rather than the primary repression, but merely stopped at a conjecture [2].

Amnesia involves infantile amnesia and psychogenic amnesia. The former illustrates the absence of childhood memories between 2 to 5 ages, the latter is the development of severe retrograde amnesia in defect of significant anterograde amnesia, which cannot be linked with attributable brain damage.

On one hand, for infantile amnesia, James A. Chu (1999) concluded his research due to substantial feedback of all types of abuse in childhood, especially physical or sexual abuse which reported partial or total amnesia, that chronic abuse with early age at onset is correlated to the level of amnesia for abuse memories [3]. The participants in this study reported a high level of amnesia, and a large proportion of their recovered memories could be independently corroborated. There was a criterion for testing corroboration during the experiment, which supported participants who had complete amnesia to attempt to confirm their recovered memories, and as a result, the corroboration rate was $89 \%$ as high as the report by Herman and Schatzhow (1987) that was $83 \%$ patients who were recruited from clinical population and treated from abuse memory.
On the other hand for psychogenic amnesia, studies on this field recommended that there would be memory loss that encompasses all autobiographical memory and any sense of personal identity which could be called a fugue state due to experience of psychologic trauma [4]. An example of a wartime fugue was given by Schacter (1996). During World War II, it is said that an Australian soldier converted to be traumatized as a German warplane swooped down towards him, and he tried to fight back before faint. A month later, he was aware of his memory loss and went to a Syrian hospital. Indeed he was constantly in fugue state for this period, searching for asylum nearby camp which was hearsay in Syria [5]. Although it is impossible to conduct studies with highly controlling at the occurrence, on account of existing information, it could be deduced as sudden and severe obstacle in mnemonic functioning in the face of menace.

Dissociation is the separation of normally related mental processes that once united, leading in extreme cases to disorders such as multiple personality which illustrates that an individual evolves separate personalities and undergo memory loss of particular events when each personality dominates. A typical example of this disorder is Shirley Ardell Mason, which is known as Sybil. Shirley had 16 personalities after suffering severe sexual abuse from her father. It was Dr. Cornelia Wilbur who explored these atrocities during her therapy sessions with Shirley while Shirley came to resolve her emotional problems and blackouts.

\subsection{False recovered memory}

\subsubsection{Suggestibility}

As Elizabeth Loftus claimed, such memories were often regained during psychotherapy when patients were particularly vulnerable to suggestions. However, during the treatment, inappropriate wording used by therapists could become inductive interrogation which generated false memory in patients' alleged recovered memory. The false memory produced in this way would be named as suggestibility. For example, when patients came to therapists for help while they had some existing symptoms, a number of therapists might seem to have persuaded them that these symptoms might in virtue of previous abuse. Although it may occur rarely, it does happen.

In Loftus and Pickrell (1995), it has been proven that it is possible to implant negative false memory in childhood memory as a "recovered memory". A seminal study was conducted with 24 participants as they were presented with four 4-to-6-years-old stories whereas three of them were true stories except one. All the true stories which indeed occurred were acquired from 
participants' relatives, likewise the circumstances of the false-story setting "lost in a shopping mall" because researchers needed specific details to confirm that the fake story was conceivable and never happened before.

Each participant was subsequently asked to answer which events they recognized more and then recalled more minutiae of these events. Later, two interviews with one-week intervals were conducted in the identical code - subjects were prompted about the four stories and required for further descriptions. A rate of mnemonic clarity was also given after each interview. As a result, 5 out of 24 participants falsely recalled the fake story. This outcome might seem less notable, but it still presented the possibility of implanting negative false memory. Moreover, a later study which was titled "A picture is worth a thousand lies", done by Kimbereley Wade and her colleagues in 2002, its results offered this field with $50 \%$ of subjects creating false memories, which was a large proportion. Thus, to some extent, this theory could be practically utilized in memories with regardless of content which involved recovered memories such as abuse.

\subsubsection{Hypothesis on other causes}

As mentioned before, false memories also comprise concepts of source misattribution, bias, confabulation. Therefore, there could be a hypothesis that false recovered memories may be led by other reasons rather than suggestibility, which is overlooked in usual cases.

Source misattribution indicates misremembering the source of learnt information. As an example, in daily scenarios plagiarism may take place among new songs of professional singers who always claim that these works are pieces of originality, however, a large proportion of them may actually have heard of the existing song before, and unconsciously remembered part of it. With long intervals, they falsely believe that these popping-out rhymes are neoteric ideas. This situation would literally be the consequence of being confused with mnemonic sources.

Hence, if source attribution is associated with recovered memories, individuals could misattribute the mnemonic source of being abused. Assumed that a patient saw a piece of news on the television and memorized it intentionally or not when he or she was at an early age, which was about a little girl who was being both sexually and physically abused by her uncle. After many years, while others remind the patient of events of abuse, there could be a greater chance that he or she would mistakenly recall the previous news as recovered self-experience. That is one technique for how false recovered memories would develop.

Bias is the alteration of memory due to later experience or knowledge, which could be divided into two situations: proactive interference, when an old memory makes it unavailable to the new one; retroactive interference, when a new experience interferes recalling old memory. People often record a never-happened event which is merely inferred based on existing knowledge as self-experience. A previous study found that when subjects were requested for reading a text of having lunch in a restaurant, though it did not mention the ordering step in content, subjects could still erroneously recall it because subjects have already been familiar with this series of scripts.

Correspondingly, using "The Case of Ms. W" (cited from "The science of false memory") for reference, when a female was robbed by a strapping man in a dark alley, she might make the statements afterward as she would be raped if she resisted during taking the testimony. Nonetheless, the detailed examination of the crime scene which was conducted by officers and forensic investigators was also failed to recover any single item of relevant physical evidence whereas multiple felonies were reported by the patient that represented the testimony might be distorted.

Confabulation implies filling in the gaps if individuals do not remember all the details. The common research method in laboratory was offering subjects with a Life Events Inventory (LEI) which contained multiple childhood events and asking for rating likelihood of each event occurring at a given age. A two-week interval after, subjects needed to fill the list again while imagining certain events and rated them. The results showed that participants' perception of the probability of that event happening was significant increased after imagining. This is indeed a broader concept because once a patient has been kept considering and imagining anticipant events to happen, irrespectively what content the imagination was, in certain cases, the expectations and imaginations would turn into actually fake memories. Accordingly, the recovered memories could solely be the consequence of imagination inflation.

\subsection{Discussion}

It has been verified that both true and false recovered memories are solid and even relatively universal, yet it is hard to surely recognize the facticity of such memories [6].

According to the existed research, 90 percent of the claimants of being abused are female who are over 25 years old, nineteen individuals even filed the report at the age of 50 or older until age 68. Additionally, merely 305 designated the time span over the alleged sexual abuse out of 736 reports. It follows that the majority of their complainants relied on early childhood images as the basis of their lawsuits despite the reliability of their memories of these events from such an early age is heavily low, especially with alike prolonged intervals, as they cannot recall the distinct details [7]. 
In addition, by the reason of the foregoing, false recovered memories would have more causes of formation compare to truly recovered memories as the memories could be distorted regardless of external or internal factors while individuals who held no belief in their experience are easily swayed. Simultaneously, lying is also a cause which cannot be eliminated.

Thus, it could be deduced that the possibility of regaining false recovered memories in cases is higher in contrast to truly recovered memories. Apart from this, a mass of reported incidents could be fake as well when officers do not have the ability or sufficient evidence to identify with such mass of case reports, so only a matter of monotonous testimony built upon the event sent innocent people to prison.

\section{APPLICATIONS}

\subsection{How to detect}

False recovered memories which lead by suggestibility could be revealed by recordings of the interview. It could be checked whether or not any suggestive features appeared during the conversation. The Deese, Roediger and McDermott (DRM) task is currently used to investigate source attribution, yet it cannot be conducted as an appropriate experiment outside the laboratory under extreme conditions to examine the reliability $[8,9]$. There is also a leading way which is to survey everything in subjects' life that fits their description of the event, however, it is not realistic. In like manner, bias and confabulation are both difficult to distinguished in daily, particularly in courts, which is why physical evidence will always be the strongest because memories cannot be preciously measured by computer.

\subsection{How to avoid}

Previously, there was no such method to help plenarily preventing the development of false memories, yet some efforts could still be made. On one side for internal elements, patients should form a habit of keeping a diary. If it is chaotic to bear every single detail in mind, all the journals would be great tools for recalling. Plus, training of cognitive control also helps to stay away from false memories as reported by psychologist Jason $\mathrm{M}$. Watson, he suggests that people with preferable mentalfunction control are less sensitive to false memory [10]. On another side for external elements, coadjutants should make answers without any inductive features which may sway patients or make them confused. Taking the typical Yes-no question as an example, Interviewees are requested to agree or disagree with pertinent items of information.

\section{CONCLUSION}

In summary, this paper indicates that both true and false recovered memories remain yet the probability of regaining false recovered memories is higher than the true ones, and there could be more cases of false recovered memories out of reports. For the limitations of this paper, the amount of given examples is small, which does not contain sufficient evidence in each concept. In addition, the hypothesis of false memories in source attribution, bias as well confabulation is not mature enough with less supporting ideas from prior research. As well as the methods of detecting false recovered memories from four different sides, no representative ones can be flexibly applied in actual cases, and no researchers have found a way to correctly, effectively keep away from false memories. For improvements of this paper, it would be better if a larger number of instances are summarized and used in the explanation of key approaches, exclusively source attribution, bias and confabulation. Likewise, surveys or interviews about false recovered memories can be conducted in advance to collect more real comments and data daily. In the future expectation, researcher may focus on the aspect of recognizing true and false recovered memories in an accurate way which is indeed meticulous to each category of false memories, because it would be the most capable aide in criminal courts which can rescue vast innocent people.

\section{AUTHORS' CONTRIBUTIONS}

This paper is independently completed by Bonan Chen.

\section{ACKNOWLEDGMENTS}

Support for data collection was mainly provided by the Google browser and Bing browser. I thank my TA Mina, educational administration Joy, thesis advisor Olivia in academic fields, as well as the families and friends who have so generously given of their time to make this work possible.

\section{REFERENCES}

[1] Brainerd, C., \& Reyna, V. (2005). The science of false memory. New York: Oxford University Press.

[2] Williams, L. M. (1994). Recall of childhood trauma: A prospective study of women's memories of child sexual abuse. Journal of Consulting and Clinical Psychology, 62(6), 1167-1176. https://doi.org/10.1037/0022-006X.62.6.1167

[3] James A. Chu, Lisa M. Frey, Barbara L. Ganzel, and Julia A. Matthews. (1999). Memories of Childhood Abuse: Dissociation, Amnesia, and Corroboration. American Journal of Psychiatry 1999 156:5, 749. 
755.

https://ajp.psychiatryonline.org/doi/abs/10.1176/ajp .156.5.749

[4] Harrison, N. A., Johnston, K., Corno, F., Casey, S. J., Friedner, K., Humphreys, K., Jaldow, E. J., Pitkanen, M., \& Kopelman, M. D. (2017). Psychogenic amnesia: syndromes, outcome, and patterns of retrograde amnesia. Brain : a journal of neurology, 140(9), 2498-2510. https://doi.org/10.1093/brain/awx 186

[5] P. Bright, M.D. Kopelman. (2014). Memory, Autobiographical. Encyclopedia of the Neurological Sciences (Second Edition) Academic Press, 2014, Pages 1036-1038, ISBN 9780123851581. https://doi.org/10.1016/B978-0-12-3851574.00453-X.

[6] Freyd, J.J. (2020). What about Recovered Memories? Retrieved 23 May 2021 from http://pages.uoregon.edu/dynamic/jjf/whatabout.ht $\mathrm{ml}$

[7] Woolston, C. (2021). Making the case against memories as evidence. Retrieved 1 June 2021, from https://knowablemagazine.org/article/society/2017/ making-case-against-memories-evidence

[8] James M. Lampinen, Jeffrey S. Neuschatz, David G. Payne. (1999). Source attributions and false memories: A test of the demand characteristics account. 1999 Psychonomic Bulletin \& Review, Volume: 6, Issue: 1, pp 130-135 DOI: 10.3758/BF03210820

[9] Pardilla-Delgado, E., \& Payne, J. D. (2017). The Deese-Roediger-McDermott (DRM) Task: A Simple Cognitive Paradigm to Investigate False Memories in the Laboratory. Journal of visualized experiments: JoVE, (119), 54793. https://doi.org/10.3791/5479

[10] Increased cognitive control helps prevent false memories. (2021). Retrieved 2 June 2021, from https://www.apa.org/monitor/feb05/cognitive 